\title{
Dípteros ectoparásitos hematófagos: ¿reservorios potenciales del virus del dengue?
}

\author{
Álvaro Aguilar Setién', Anahí García Baltazar', Ignacio Olave Leyva², Mónica Salas Rojas, \\ Vadim Pérez Koldenkova ${ }^{3}$, Mariem Pérez-Peña García', Nidia Aréchiga Ceballos', Guillermo Gálvez \\ Romero ${ }^{1}$, Edgar Olivier López Villegas ${ }^{5}$, Juan Bibiano Morales Malacara ${ }^{6}$ y Cenia Almazán Marín ${ }^{1}$ \\ 'Unidad de Investigación Médica en Inmunología, Hospital de Pediatría del Centro Médico Nacional Siglo XXI, Instituto Mexicano del Seguro Social \\ (IMSS), Ciudad de México; 'Instituto de Ciencias Agropecuarias, Universidad Autónoma del Estado de Hidalgo, Tulancingo, Hgo.; ${ }^{3}$ Laboratorio \\ Nacional de Microscopía Avanzada, Centro Médico Nacional Siglo XXI, IMSS, Ciudad de México; ${ }^{4}$ Instituto de Diagnóstico y Referencia \\ Epidemiológicos, Ciudad de México; ${ }^{5}$ Departamento de Investigación-SEPI, Laboratorio Central de Microscopía, Escuela Nacional de Ciencias \\ Biológicas, Instituto Politécnico Nacional, Ciudad de México; ${ }^{6}$ Unidad Multidisciplinaria de Docencia e Investigación, Facultad de Ciencias, \\ Universidad Nacional Autónoma de México, Juriquilla, Qro., México
}

\section{Resumen}

Recientemente se reportó la presencia de anticuerpos y de ARN del virus del dengue (VD) en mamíferos silvestres neotropicales, incluyendo Desmodus rotundus, por lo que en un trabajo previo se buscó el VD en dípteros ectoparásitos de estos quirópteros, encontrándose un alto porcentaje (39.6\%) positivos. Para comprobar la susceptibilidad de estos ectoparásitos al $V D$, en este trabajo se realizaron infecciones experimentales con VD2 de órganos de Strebla wiedemanni y de Melophagus ovinus usando como control células C6/36. Se determinaron los títulos virales (unidades formadoras de placas [UFP]/ml) a las 0, 48 y 96 horas postinfección (pi). Los órganos infectados fueron sometidos a microscopía electrónica y pruebas de inmunofluorescencia (IF) utilizando conjugados específicos contra el VD. Los órganos infectados de ambas especies de ectoparásitos replicaron el VD a títulos similares a los obtenidos con la línea celular C6/36 ( $\geq 10^{6}$ UFP/ml). La microscopía electrónica y la IF mostraron replicación del VD en el tubo digestivo, las traqueolas, los órganos reproductores de los machos (no en las hembras) y las células de las glándulas de leche (GL) de ambas especies. En los cuerpos grasos de las GL de M. ovinus se observaron zonas con una alta afinidad por el VD. Se demuestra la susceptibilidad de S. wiedemanni y M. ovinus al VD y con ello su probable papel como reservorios silvestres de este virus.

PALABRAS CLAVE: Virus del dengue. Strebla wiedemanni. Desmodus rotundus.

\begin{abstract}
Recently, the presence of antibodies and dengue virus (DV) RNA in neotropical wild mammals, including Desmodus rotundus, was reported. In a previous study, DV was also found in a high percentage (39.6\%) of ectoparasitic hematophagous dipters specifics of these hematophagous bats. In order to verify the susceptibility of these ectoparasites to DV, in this work experimental infections with VD2 of organs explants of Strebla wiedemanni and of Melophagus ovinus were performed using C6/36 cells as control. Viral titers (UFP/mL) were determined at 0, 48 and 96 hrs pi. Infected organs were observed by electron microscopy and under the confocal microscopy indirect immunofluorescence (IIF) using specific conjugates against DV. The infected organs of both species of ectoparasites replicated DV at titers similar to those obtained with the C6/36 cell line ( $\geq 10^{6} \mathrm{UFP} / \mathrm{mL}$ ). Electron microscopy and IIF showed DV replication in the digestive tract, tracheoles, reproductive organs of males but not in females, and milk glands (MG) of both species. In the fatty bodies of the MG of M. ovinus, zones with a high
\end{abstract}

\author{
Correspondencia: \\ Álvaro Aguilar Setién \\ Cuauhtémoc, 330 \\ Col. Doctores \\ C.P. 06720, Ciudad de México, México \\ E-mail: estiviro@ hotmail.com
}

Fecha de recepción: 07-08-2017

Fecha de aceptación: 07-09-2017

DOI://dx.doi.org/10.24875/GMM.M17000009
Gac Med Mex. 2017;153;Sup 2:S82-S90

Contents available at PubMed

www.anmm.org.mx 
affinity for the DV were observed. In this work the susceptibility of S. wiedemanni and M. ovinus to DV was demonstrated and consequently the probable role of this ectoparasites as wild reservoirs of DV.

KEY WORDS: Dengue virus. Strebla wiedemanni. Desmodus rotundus.

\section{Introducción}

En forma general podemos decir que hay una tendencia a estudiar con mayor profundidad a los vectores tales como el mosquito Aedes aegypti, que están adaptados al entorno humano y que mantienen los ciclos llamados urbanos de las arbovirosis importantes como el dengue, el Chikungunya y el Zika. Por razones lógicas, se conoce menos de los reservorios o vectores de áreas silvestres o poco exploradas por el hombre.

A medida que nos adentramos en el estudio de la biodiversidad, se observa que las interacciones existentes entre los organismos son más complejas de lo que se creía o se esperaba. De esta manera, actualmente sabemos que algunos patógenos humanos transmitidos por vector, no solo se replican en una especie determinada de artrópodo, sino que pueden adaptarse fácilmente a otros. El ejemplo más claro de este fenómeno es el virus Chikungunya, con el cual se ha demostrado que una sola mutación puede modificar su afinidad por el vector de transmisión, cambiando de esta manera radicalmente su potencial epidémico ${ }^{1}$. En trabajos previos, nuestro grupo reportó la presencia de anticuerpos o de ácidos nucleicos contra el virus del dengue (VD) en varias especies de murciélagos, incluido el vampiro común Desmodus rotundus ${ }^{2-4}$. Esto nos llevó ensayar la susceptibilidad de murciélagos frugívoros al VD a fin de poder explicar los indicios de infección de los quirópteros con el VD, encontrándose una baja tasa de replicación del virus en estos animales ${ }^{5,6}$. Por otro lado, se buscó también la presencia de este virus en los dípteros ectoparásitos exclusivos de los quirópteros, como los de la familia Streblidae, encontrándose la presencia del VD en una alta proporción (39.6\%) de estos artrópodos ${ }^{7}$.

En el presente trabajo se estudia la susceptibilidad a la infección con DV de dípteros ectoparásitos específicos de los quirópteros (familia Streblidae) utilizando como control dípteros ectoparásitos específicos de los ovinos (familia Hippobosidae). Estos dípteros están relacionados filogenéticamente y presentan características evolutivas similares.

En el caso de los mosquitos de la familia Culicidae, como los géneros Aedes y Anopheles, existen modelos de laboratorio de infección experimental bien establecidos. Esto se facilita por el hecho de que estos animales presentan diferentes fases en sus ciclos de vida que no están ligadas a los huéspedes vertebrados de los que se alimentan. Por otro lado, estos animales tienen la capacidad de alimentarse de sangre de varias especies de vertebrados. La dependencia tan íntima que existe entre los ectoparásitos de las familias Streblidae e Hippobosidae y sus hospederos ha hecho difícil el establecimiento de modelos de laboratorio de infección de estos animales. En el presente trabajo se optó por el cultivo de los órganos de los ectoparásitos ex vivo a fin de explorar la receptividad y la permisividad de estos dípteros al VD.

\section{Métodos}

\section{Recolección de ectoparásitos y cultivo de órganos}

Mediante pinzas para microcirugía se tomaron ejemplares de dípteros ectoparásitos Strebla wiedemanni a partir de la piel de murciélagos $D$. rotundus capturados en un refugio localizado en el Municipio de Progreso, en el Estado de Hidalgo, México $\left(20^{\circ} 5^{\prime}\right.$ $00^{\prime \prime} \mathrm{N} 99^{\circ} 11^{\prime} 00^{\prime \prime} \mathrm{O}$ ). Los murciélagos fueron capturados utilizando redes de niebla instaladas a la salida del refugio y con redes entomológicas en el interior del mismo.

Utilizando pinzas de cirugía simples con punta roma se tomaron ejemplares de dípteros ectoparásitos Melophagus ovinus de la piel de borregos criollos de un hato localizado en el Municipio de Singuilucan, en

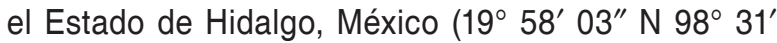
04" O).

Una vez en el laboratorio, los ectoparásitos recolectados fueron sometidos a temperatura de refrigeración (entre 4 y $8^{\circ} \mathrm{C}$ ) con el fin de reducir su actividad para que fueran manipulables, y fueron confirmados taxonómicamente como $S$. wiedemanni y $M$. ovinus bajo el microscopio estereoscópico. Posteriormente fueron sometidos a inmersión en alcohol etílico absoluto durante un minuto para eliminar microorganismos contaminantes de su superficie. Una vez evaporado el alcohol, los ectoparásitos se disecaron en PBS y sus 
diferentes órganos fueron separado y lavados tres veces por inmersión en PBS estéril con antibióticos (300 UI de penicilina/ml, $30 \mu \mathrm{g}$ estreptomicina/ml) y antimicóticos (nistatina $1000 \mathrm{U} / \mathrm{ml}$ ). Los órganos de cada ectoparásito fueron cultivados por separado en placas de 24 pozos de fondo plano para cultivos celulares (Falcon®, cat No 353226) en medio mínimo esencial suplementado con un $15 \%$ de suero fetal bovino (SFB) para cultivos celulares. Las placas fueron mantenidas en una incubadora a $27^{\circ} \mathrm{C}$ en atmosfera normal.

\section{Virus}

Para preparar el virus de inoculación se utilizó la línea celular C6/36 de Aedes albopictus (ATCC $®$ CRL1660 ${ }^{\text {TM}}$ ) cultivada en botellas de plástico para cultivo celular de $75 \mathrm{~cm}^{2}$ de superficie con medio esencial mínimo de Eagle (EMEM) suplementado con un $10 \%$ de SFB y mantenidas a $27^{\circ} \mathrm{C}$ en atmósfera normal, hasta obtener un monoestrato semiconfluente. Posteriormente, el medio de crecimiento fue desechado y el monoestrato se inoculó con la cepa Nueva Guinea del VD 2 con un índice de multiplicidad de la infección (MOI) de 0.1. Después de 1 hora de incubación a $27^{\circ} \mathrm{C}$, el inóculo se desechó y se adicionó medio de mantenimiento (EMEM suplementado con un $2 \%$ de SFB). Las botellas inoculadas fueron incubadas hasta observar un $80 \%$ de efecto citopático del virus (4-6 días). Se colectó el sobrenadante y fue centrifugado a $2000 \mathrm{~g}$ para clarificarlo, después de lo cual fue distribuido en alícuotas de $1 \mathrm{ml}$ que se almacenaron a $-70{ }^{\circ} \mathrm{C}$ hasta su utilización.

\section{Titulación viral}

Para determinar los títulos virales obtenidos se utilizaron placas para cultivos celulares de 24 pozos de fondo plano con monoestratos de la línea celular de riñón de hámster BHK-21. Las células BHK-21 fueron sembradas en cada uno de los pozos de la placa a razón de $3 \times 10^{5}$ células por pozo en $1 \mathrm{ml}$ de EMEM suplementado con un $10 \%$ de SFB, e incubadas aproximadamente durante 2 días a $37^{\circ} \mathrm{C}$ en una atmósfera con un $5 \%$ de $\mathrm{CO}_{2}$ hasta lograr monoestratos confluentes. El medio de crecimiento fue desechado y los monoestratos fueron inoculados con $200 \mu \mathrm{l}$ de diluciones logarítmicas base 10 del virus. Después de 1 hora de incubación a $37^{\circ} \mathrm{C}$, el inóculo fue desechado y los monoestratos fueron cubiertos con una mezcla de EMEM, carboximetilcelulosa (0.8\%) y SFB
(5\%). Después de 5 días de incubación a $37{ }^{\circ} \mathrm{C}$ en atmósfera con un $5 \%$ de $\mathrm{CO}_{2}$, los monoestratos fueron fijados con formaldehído al 4\% en PBS y teñidos con una solución de cristal violeta. Las placas líticas producidas por el virus fueron contabilizadas para cada dilución del virus y los resultados se expresaron en unidades formadoras de placas (UPF) por mililitro ${ }^{5}$.

\section{Inoculación de los órganos de los dípteros ectoparásitos}

Después de 24 horas de incubación y de haber constatado su viabilidad mediante la prueba de viabilidad $\mathrm{MTT}^{8}$, y observando el movimiento peristáltico de los restos del sistema circulatorio, los órganos fueron infectados adicionando $50 \mu \mathrm{l}$ de la suspensión del VD2 Nueva Guinea con $1 \times 10^{5.2}$ UFP/ml. Se utilizaron como control órganos no infectados, inoculado únicamente con $50 \mu \mathrm{l}$ de PBS. Por otro lado, a fin de tener un punto de referencia de la replicación del VD, al mismo tiempo se inoculó con la misma dosis de virus una botella de $24 \mathrm{~cm}^{2}$ de superficie con un monoestrato confluente de células $\mathrm{C6/36}$. Los órganos y la botella con células $\mathrm{C} 6 / 36$ fueron incubados a $27^{\circ} \mathrm{C}$ en atmósfera normal.

Se colectaron $250 \mu \mathrm{l}$ de sobrenadantes de cada órgano inoculado, de los órganos controles y de las células $\mathrm{C} 6 / 36$ inoculadas, a las 48 y 96 horas pi, los cuales fueron almacenados a $-70{ }^{\circ} \mathrm{C}$ para la posterior titulación del VD por medio de la cuantificación de UFP/ml. A las 96 horas pi los órganos fueron fijados con Citofix/Citoperm $®$ (siguiendo las instrucciones del fabricante) para la detección del virus por medio de inmunofluorescencia.

Parte de los órganos fueron fijados con glutaraldehído al $2 \%$ en tampón de cacodilatos para su observación en un microscopio electrónico de transmisión.

\section{Inmunofluorescencia y microscopía electrónica}

A fin de determinar la localización del VD, los órganos fijados se lavaron tres veces con Perm/wash $®$ siguiendo las recomendaciones del fabricante. Como anticuerpo primario se utilizó una mezcla a partes iguales de los anticuerpos comerciales producidos en conejos, uno contra la proteína NS5 del VD (Gentex GTX cat. No. 103350) y el otro contra la proteína NS1 (Gentex GTX cat. No. 124243), siguiendo las recomendaciones del fabricante. Como anticuerpo 
secundario se utilizó un anticuerpo comercial policlonal antigammaglobulinas de conejo, conjugado a la fluoresceína (Sigma cat. N. F-0382). En algunas ocasiones se utilizó el colorante DAPI (Sigma Aldrich, cat No D 8417-IMG) a una concentración de $100 \mu \mathrm{g} / \mathrm{ml} \mathrm{a}$ fin de resaltar los núcleos celulares.

Una vez teñidos, los órganos fueron montados en portaobjetos utilizando Vectashield@, y se observaron en un microscopio confocal Nikon Te Eclipse equipado con una unidad de adquisición de imágenes A1. La observación inicial de las preparaciones y la toma de panoramas generales se hizo con objetivos secos $10 \times 020 \times$ (apertura numérica $=0.5$ y 0.7 , respectivamente). La visualización de los detalles de las muestras se llevó a cabo con un objetivo $60 x$ (NA = 1.4) de inmersión de aceite. Los colorantes empleados en la tinción fueron excitados utilizando láseres de 405 nm (DAPI) y 488 (fluoresceína), integrados en el equipo. Para distinguir la fluorescencia específica del anticuerpo acoplado a la fluoresceína (canal verde) de la autofluorescencia propia del tejido, esta última se adquirió de manera adicional en el canal rojo, mediante excitación con el láser integrado de $561 \mathrm{~nm}$. La excitación fue realizada de manera secuencial para evitar la filtración de la emisión de banda ancha de DAPI en el canal correspondiente a la fluoresceína. Las imágenes fueron obtenidas y analizadas directamente en el software NIS Elements v.4.50 del microscopio.

Las fracciones de los órganos fijados en glutaraldehído fueron incluidas en metacrilato para la obtención de cortes ultrafinos, que se contrastaron con metales pesados para su observación en un microscopio electrónico de transmisión siguiendo la metodología estándar.

\section{Resultados}

Se infectaron con VD cinco tubos digestivos, tres órganos genitales de hembras, dos órganos genitales de machos y tres glándulas salivales de $S$. wiedemanni. De M. ovinus se infectaron siete tubos digestivos, siete aparatos genitales de hembras y cuatro glándulas salivales. Por el reducido tamaño de los ectoparásitos, principalmente los de la familia Streblidae, los órganos contenían restos de tejidos de estructuras del aparato respiratorio, de los tubos de Malpigio y otras estructuras del tejido conectivo, circulatorio y nervioso, ya que resultaba difícil separarlos sin dañar los órganos. Las glándulas salivales de ambas especies estudiadas mostraron poca o nula viabilidad mediante la prueba MTT, por lo que fueron descartadas.

\section{Resultados de la titulación viral}

La figura 1 nos muestra la producción de virus por los órganos inoculados. Podemos observar que la producción viral en todos los órganos aumenta de manera progresiva hasta alcanzar el valor más alto a las 96 horas (Fig. 1). Los títulos obtenidos en los sobrenadantes de los órganos inoculados con VD2 (10 ${ }^{6.5} \mathrm{UFP} / \mathrm{ml}$ en promedio) son similares a los que se obtienen en las células C6/36 (106 UFP/ml).

\section{Inmunofluorescencia}

La observación en el microscopio confocal de los órganos infectados con DV, teñidos con un conjugado fluorescente dirigido contra el VD, nos mostró que existen tejidos que parecen tener una afinidad muy grande hacia el VD: los traqueoblastos de traqueolas del sistema respiratorio de $S$. wiedemanni (Fig. 2) y las estructuras de las células grasas de las «glándulas de leche» del aparato reproductor de las hembras de M. ovinus (Fig. 3). Con respecto a las traqueolas, cabe señalar que se encontró fluorescencia específica del VD en el cuerpo de traqueoblastos de pequeñas ramificaciones y de la pared de los mismos (Fig. 2). Con respecto a las estructuras de las células grasas, se observaron áreas delimitadas con tinción específica del VD rodeadas por glóbulos granulados no fluorescentes, además de pequeñas células nucleadas con fluorescencia específica en el citoplasma (Fig. 3).

Las células del sistema digestivo de $M$. ovinus muestran replicación del VD en el interior de su citoplasma, al igual que las de $S$. wiedemanni, localizándose en este último ectoparásito grandes áreas de fluorescencia en algunos casos (Fig. 4).

\section{Microscopía electrónica}

En los estudios de microscopía electrónica se observaron grandes cantidades de partículas del VD en las células de la pared, en el lumen y entre las vellosidades del sistema digestivo (Fig. 5). En las traqueolas se encontraron partículas virales emergiendo de la pared hacia la luz (Fig. 6). En el aparato reproductor de los machos de $S$. wiedemanni se observó una gran cantidad de partículas virales compartiendo espacio con espermatozoides (Fig. 7). Por 


\section{S. wiedemanni}

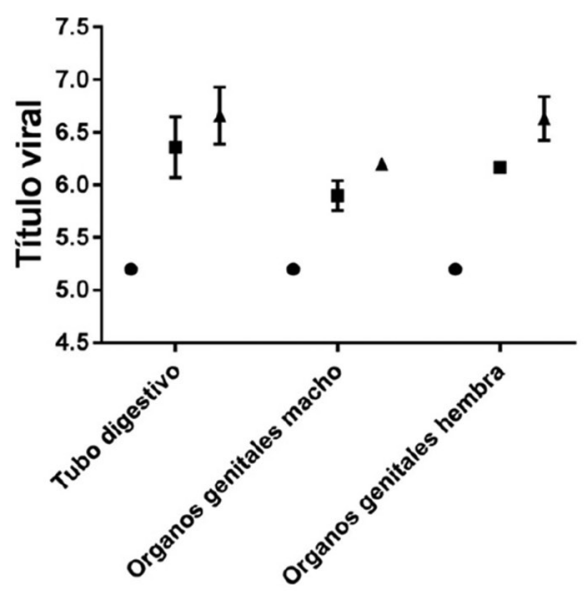

\section{M. ovinus}

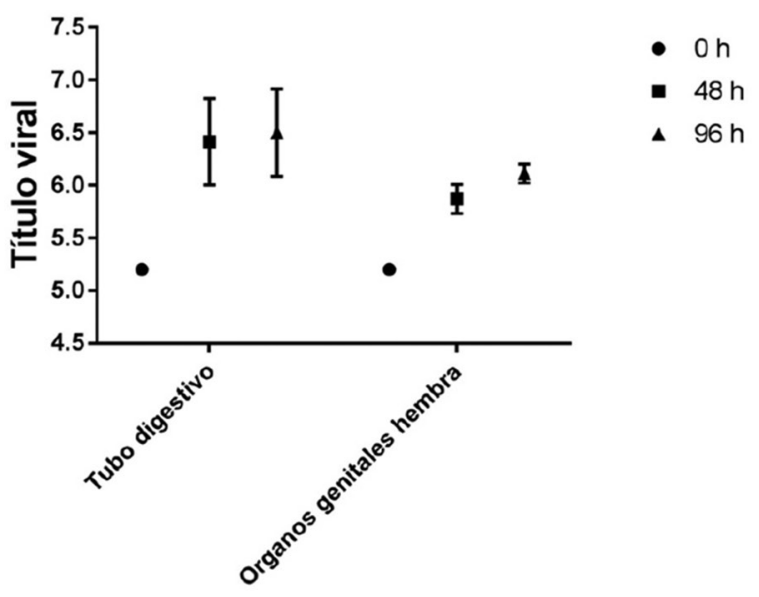

B

Figura 1. Titulación del virus del dengue a partir de sobrenadantes colectados a las 48 y 96 horas pi, de los diferentes órganos de Strebla wiedemanni A: y Melophagus ovinus B: inoculados. El título viral se expresa como el logaritmo base 10 del número de unidades formadoras de placas por $\mathrm{ml}(\mathrm{UFP} / \mathrm{m})$. Los órganos fueron inoculados inicialmente con $1 \times 105.2 \mathrm{UFP} / \mathrm{ml}$.

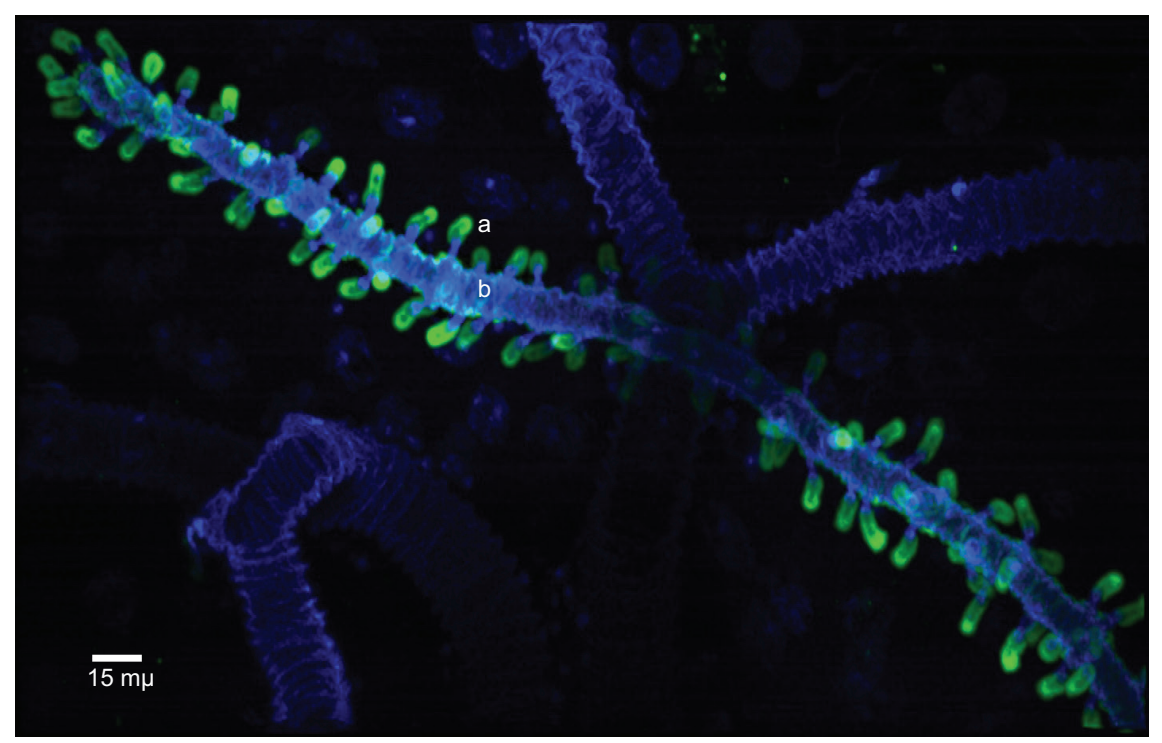

Figura 2. Traqueola de Strebla wiedemanni inoculada con VD2 (1 × $10^{5.2}$ UFP/ml), fijada 96 horas pi, teñida para pruebas de inmunofluorescencia para la detección de antígenos del virus (FITC). Núcleos celulares contrastados con DAPI. a: traqueoblastos terminales de las ramificaciones con fluorescencia específica; $b$ : traqueoblastos del cuerpo de la traqueola con fluorescencia específica.

el contrario, en los gametos de las hembras no se observaron partículas virales, solo algunas estructuras similares a las de las bacterias endosimbiontes de los artrópodos (Fig. 8).

\section{Discusión}

En el presente trabajo se demostró que las células que forman los tejidos de diversos órganos de $S$. wiedemanni y M. ovinus son capaces de replicar el VD2, ya que se observaron aumentos en los títulos virales de los órganos inoculados a las 48 y 96 horas pi (Fig. 1). Los títulos obtenidos son superiores, aunque no en forma significativa, a los que se obtuvieron con la inoculación de la línea celular C6/36 con la misma dosis. Sin embargo, es difícil hacer una comparación de los dos sistemas porque, en este primer trabajo, no se pudo determinar el número de células que se infectan en los órganos de los ectoparásitos y, por lo tanto, no es posible obtener el MOI. Watts, et al. ${ }^{9}$, al 


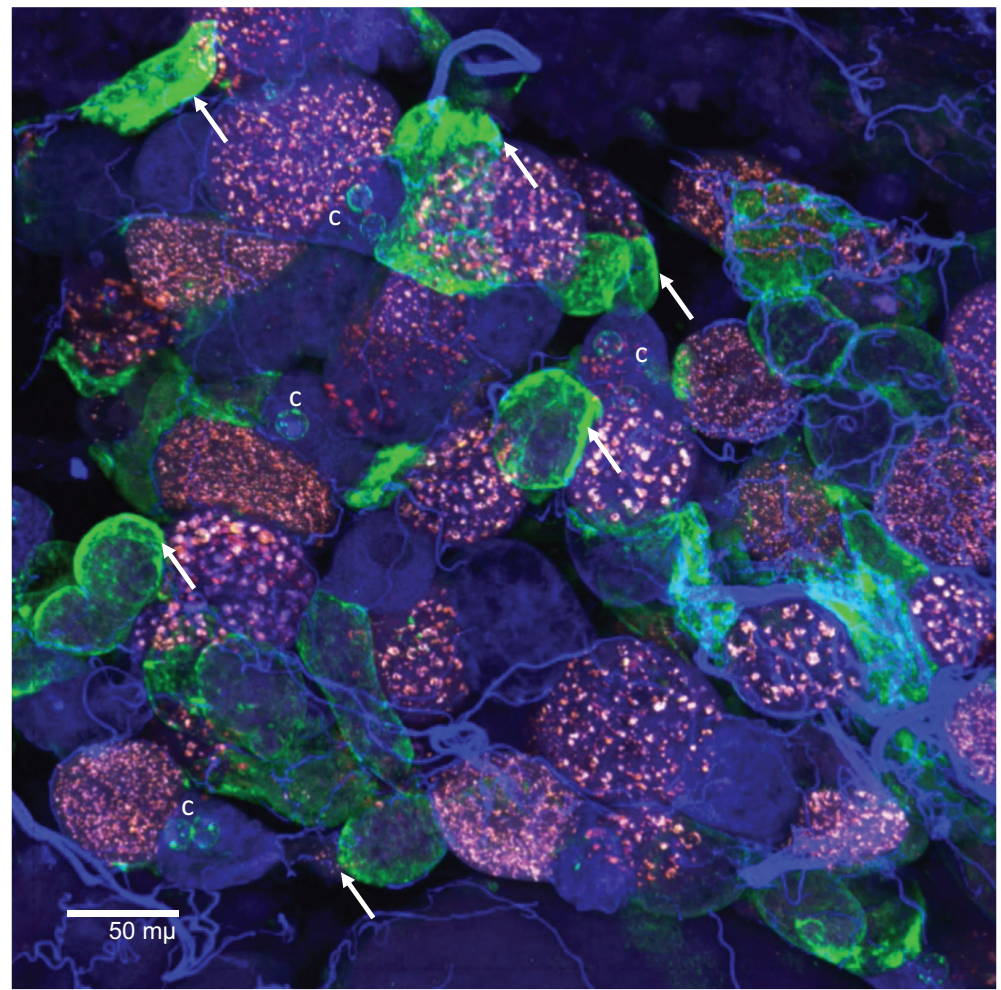

Figura 3. Imagen compuesta de cuerpos grasos de la glándula de leche de Melophagus ovinus inoculados con VD2 (1 × $10^{5.2}$ UFP/ml), fijados 96 horas pi, teñidos para pruebas de inmunofluorescencia para la detección de antígenos del virus (FITC, verde). Núcleos celulares contrastados con DAPI. Las flechas blancas muestran grandes superficies con fluorescencia específica para el DV (verde), rodeadas de glóbulos granulados sin fluorescencia específica para el VD (color rosa, observados tanto en el canal verde como en el canal rojo de la imagen obtenida); c: pequeñas células nucleadas con fluorescencia específica para el VD (verde) en su citoplasma.

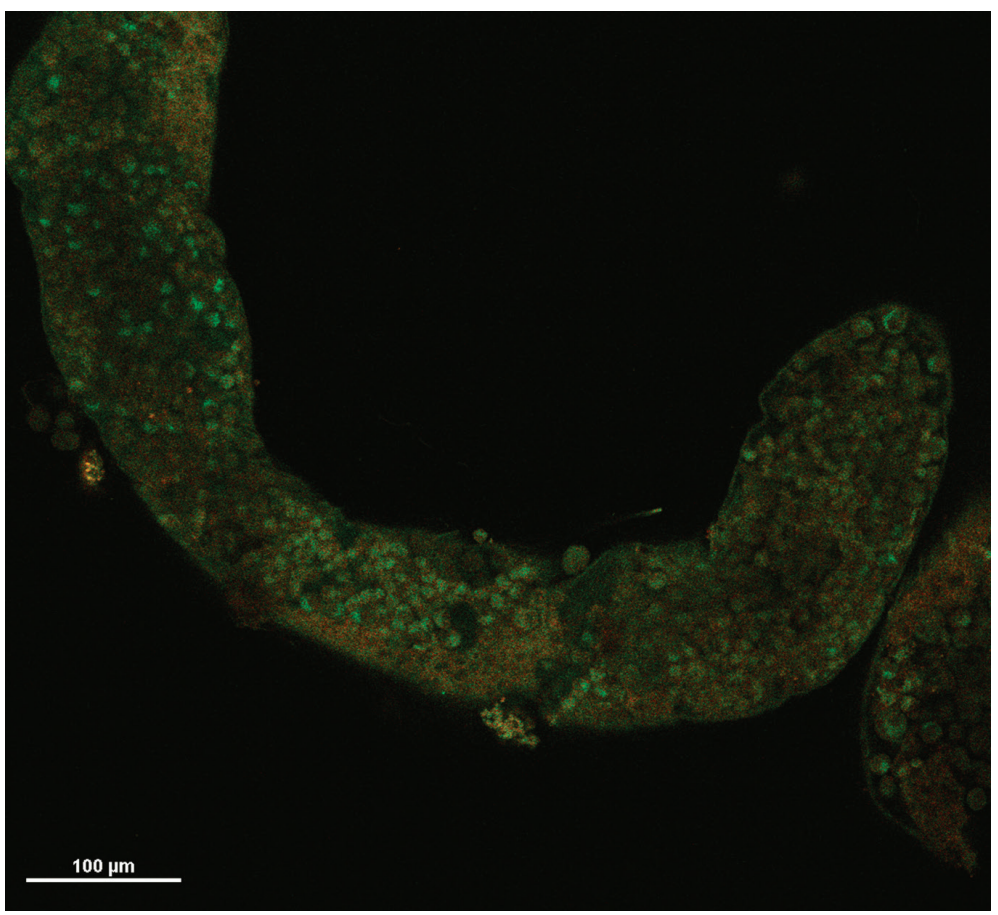

Figura 4. Segmento de tubo digestivo de Melophagus ovinus inoculado con VD2 (1 × $10^{5.2}$ UFP/ml), fijado 96 horas pi, teñido para pruebas de inmunofluorescencia para la detección de antígenos del virus (FITC). Nótese la fluorescencia específica para el VD (verde) rodeando los núcleos de las células del tejido. 

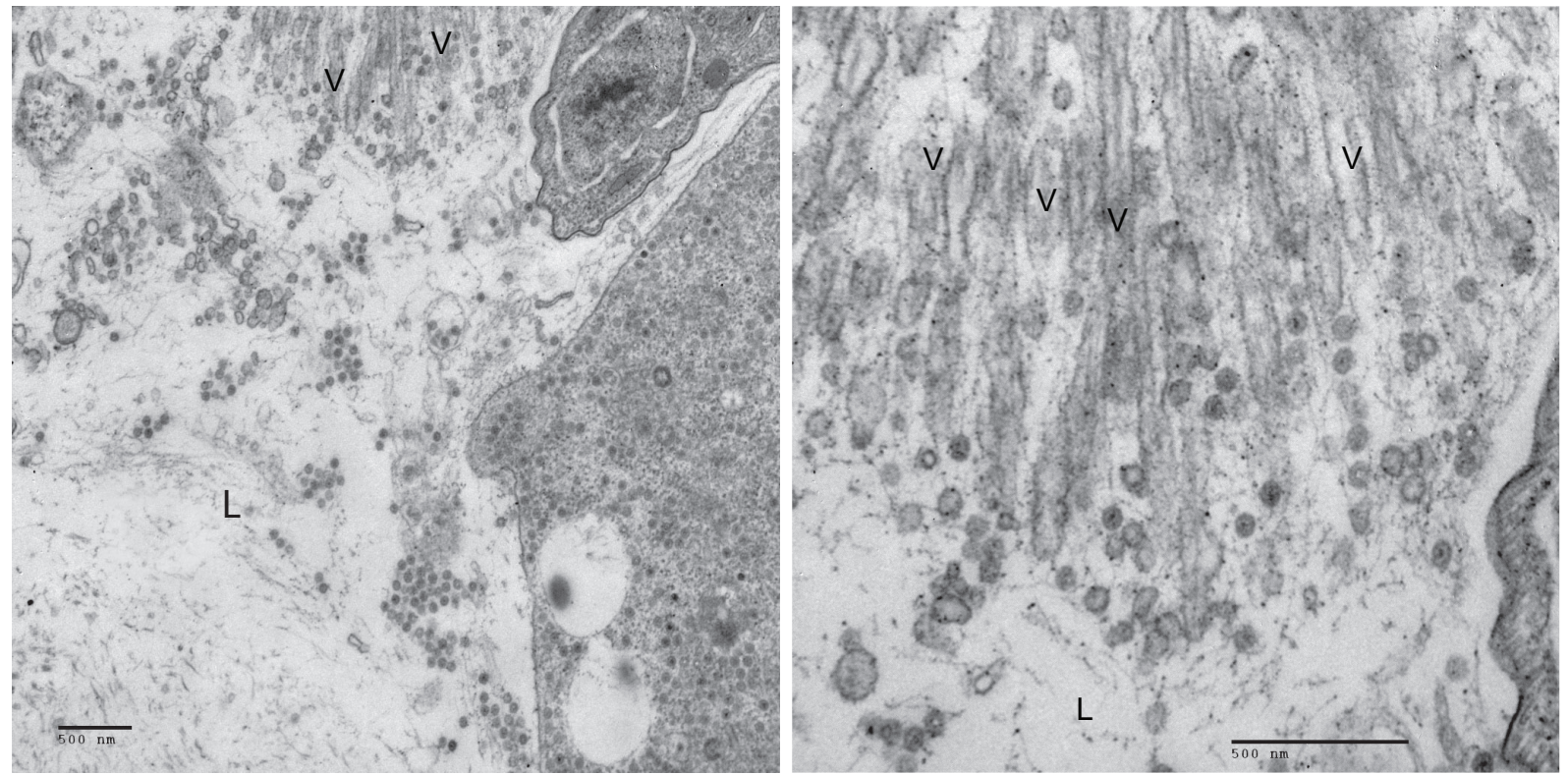

Figura 5. Corte transversal del tubo digestivo de Strebla wiedemanni inoculado con VD2 $\left(1 \times 10^{5.2} \mathrm{UFP} / \mathrm{ml}\right)$, fijado 96 horas pi para su observación en el microscopio electrónico de transmisión. A: V: vellosidades del tubo digestivo; L: luz del tubo digestivo; C: citoplasma celular. Nótese la gran cantidad de partículas virales intracelulares. B: Acercamiento. V: vellosidades del tubo digestivo; L: luz del tubo digestivo. Nótense las partículas virales entre las vellosidades.

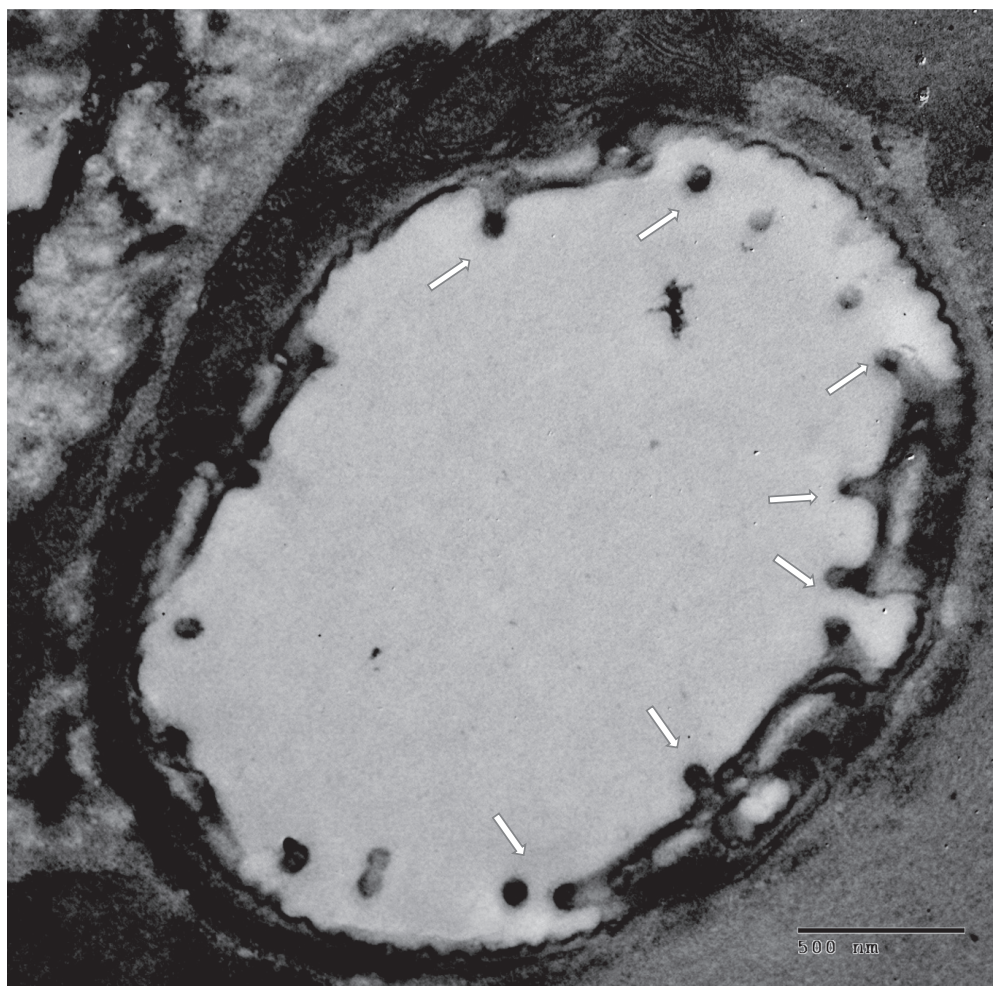

Figura 6. Corte transversal de traqueola de Strebla wiedemanni inoculada con VD2 (1 × $10^{5.2}$ UFP/ml), fijado 96 horas pi para su observación en el microscopio electrónico de transmisión. Las flechas blancas muestran partículas del virus emergiendo hacia la luz de la traqueola.

inocular mosquitos Toxorhynchites splendes por vía parenteral con VD2, encuentran títulos cercanos a $10^{8} \mathrm{UFP} / \mathrm{ml}$, pero los tiempos de incubación utilizados en su trabajo fueron mayores (más de 6 días).
El VD2 parece tener afinidad por ciertas áreas de los tejidos de los ectoparásitos estudiados, ya que se observó fluorescencia intensa específica en traqueoblastos de las traqueolas de $S$. wiedemanni y en 


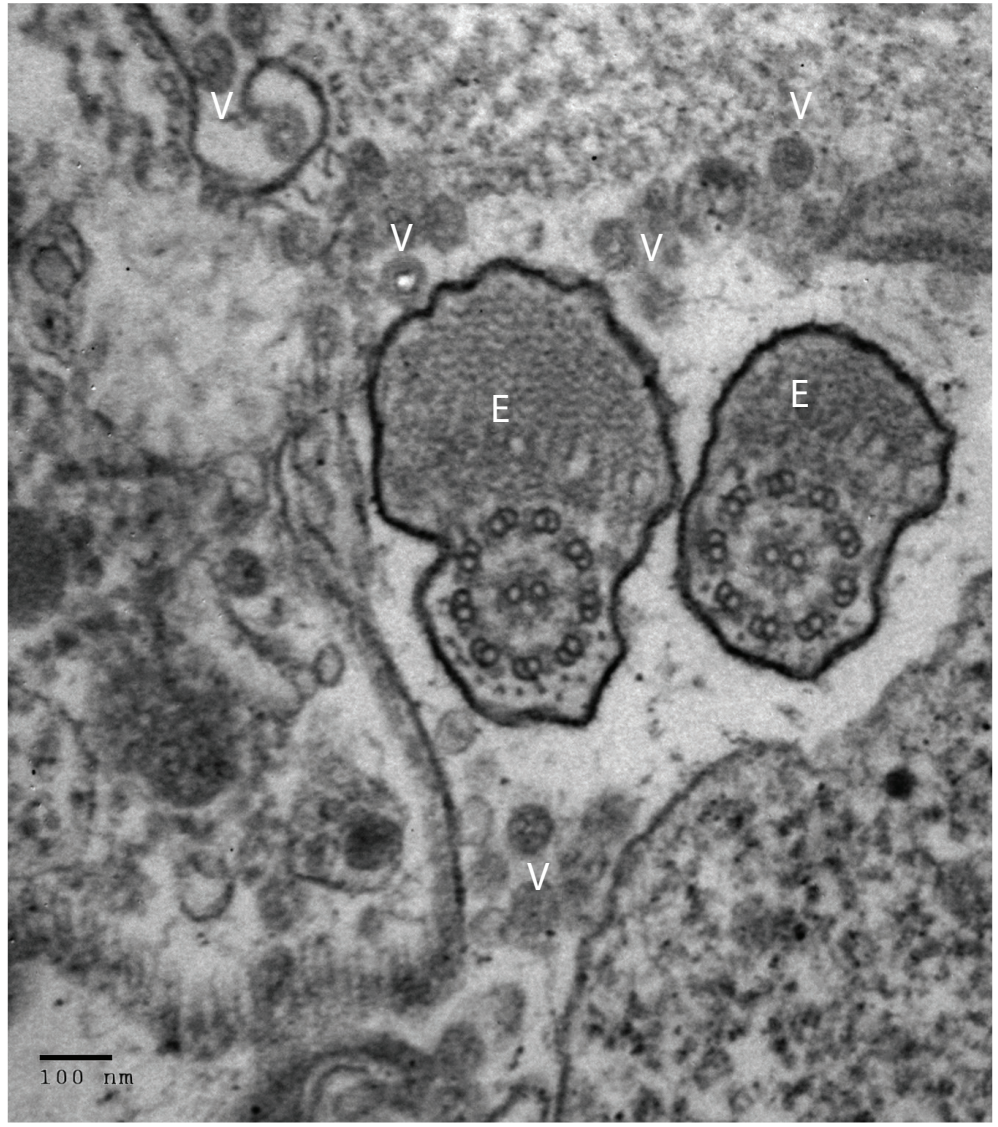

Figura 7. Corte transversal de tubo seminífero de gónada macho de Strebla wiedemanni inoculada con VD2 ( $1 \times 10^{5.2}$ UFP/ml), fijado 96 horas pi para su observación en el microscopio electrónico de transmisión. E: corte transversal de espermatozoides; V: partículas virales en la luz de los túbulos.

estructuras de los glóbulos grasos de M. ovinus. No obstante, es necesario estudiar más a fondo este fenómeno, ya que podría deberse a una unión poco específica del virus en estos lugares por la presencia de sustancias similares a las lectinas. Con respecto a las traqueolas, cabe señalar que Salazar, et al. ${ }^{10}$, en 2007, en un estudio muy completo, señalan a estos órganos como muy importantes en la diseminación del virus en $A$. aegypti. Se observaron partículas virales del VD en el aparato reproductor de los machos, y algunas en el lumen junto con espermatozoides. Sin embargo, no se hallaron en los gametos de las hembras, aunque estructuras similares a bacterias endosimbiontes estaban presentes interfiriendo con la replicación del virus en este lugar ${ }^{11}$.

En un trabajo previo de nuestro grupo se encontró la presencia de ácidos nucleicos del VD en un gran porcentaje de ectoparásitos de $D$. rotundus de la familia Streblidae (38/96 grupos de parásitos procesados, $39.6 \%)^{7}$. Este resultado inesperado planteó varias incógnitas, como la ruta del virus para llegar a estos ectoparásitos y la susceptibilidad de los mismos a la replicación del VD.
En el presente trabajo se demuestra que una cepa de referencia del VD2 es capaz de replicarse en diversos tejidos de $S$. wiedemanni y de M. ovinus. Este hecho aislado podría no tener un significado importante, pero tal capacidad, aunada a la presencia en la naturaleza de ectoparásitos de la familia Streblidae positivos al DV7, abre la posibilidad de la existencia de un reservorio silvestre diferente del VD en nuestro medio. Esta situación podría ser similar a la reportada para el virus de la fiebre amarilla, el cual, después de haber sido introducido en el continente americano a partir de África, ha establecido ciclos silvestres que involucran a simios neotropicales y mosquitos forestales de los géneros Haemogogus y Sabethes, induciendo periódicamente ciclos urbanos epidémicos que involucran a los mosquitos $A$. aegyptipi-14.

Los hábitos alimenticios del vampiro común $D$. rotundus, capaz de consumir sangre de varias especies (incluido el ser humano), podría explicar en parte cómo es que el VD pudo haber llegado a ectoparásitos tan especializados en los quirópteros: humano $\rightarrow$ vampiro común $\rightarrow$ ectoparásito. Si bien se ha demostrado que cepas de referencia del VD no se replican bien en 


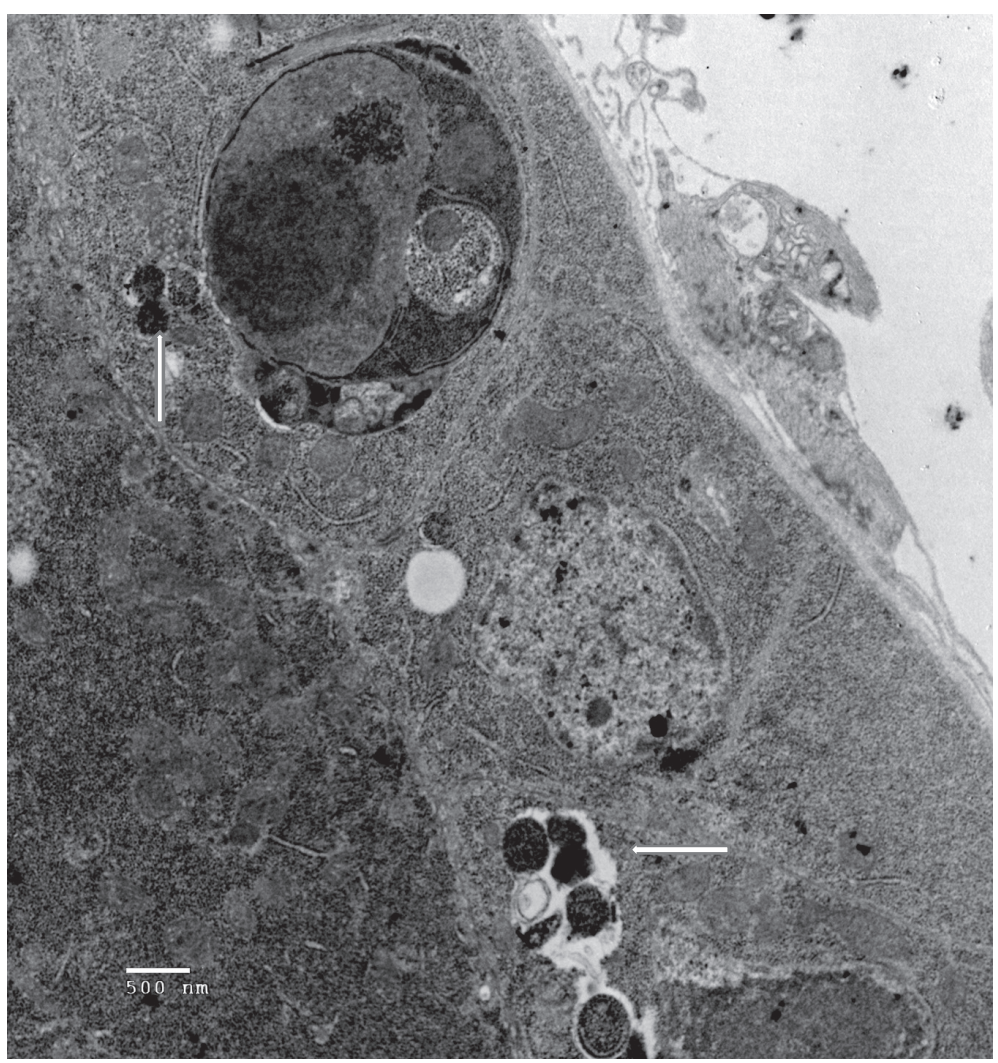

Figura 8. Corte de gónada hembra (ovario) de Strebla wiedemanni inoculada con VD2 (1 × $10^{5.2}$ UFP/ml) fijado 96 horas pi para su observación en el microscopio electrónico de transmisión. Las flechas blancas señalan estructuras similares a bacterias endosimbiontes. Nótese la ausencia de partículas del virus del dengue.

quirópteros de la familia Phylostomidae, sí existe un nivel de recuperación del virus posterior a la inoculación del mismo, el cual, al entrar en contacto con un sistema susceptible, como los dípteros ectoparásitos, podría amplificarse. Quedan varias incógnitas por despejar, principalmente el significado epidemiológico de estos hallazgos, y es necesario hacer estudios más profundos al respecto.

\section{Bibliografía}

1. Tsetsarkin KA, Vanlandingham DL, McGee CE, et al. A single mutation in chikungunya virus affects vector specificity and epidemic potential. PLOS Pathog. 2007;3:e201.

2. Aguilar-Setién A, Romero-Almaraz ML, Sánchez-Hernández $C$, et al Dengue virus in Mexican bats. Epidemiol Infect. 2008;136:1678-83.

3. Thoisy BD, Lacoste V, Germain A, et al. Dengue infection in neotropical forest mammals. Vector Borne Zoonotic Dis. 2009;9:157-70.

4. Sotomayor-Bonilla J, Chaves A, Rico-Chávez O, et al. Dengue virus in bats from southeastern Mexico. Am J Trop Med Hyg. 2014:91:129-31.

5. Perea-Martínez L, Moreno-Sandoval HN, Moreno-Altamirano MM, et al. Experimental infection of Artibeus intermedius bats with serotype-2 dengue virus. Comp Immunol Microbiol linfect Dis. 2013;36:193-8.
6. Cabrera-Romo S, Recio-Tótoro B, Alcalá AC, et al. Experimental inoculation of Artibeus jamaicensis bats with dengue virus serotypes 1 or 4 showed no evidence of sustained replication. Am J Trop Med Hyg. 2014:91:1227-34.

7. Abundes-Gallegos J, Salas-Rojas M, Galvez-Romero G, et al. Detection of dengue virus in ectoparasitic flies (Diptera: Streblidae) of the common vampire bat, Desmodus rotundus, in Progreso, Hidalgo, Mexico. Vector Borne Zoonotic Dis. 2017; in press.

8. Salas-Rojas M, Galvez-Romero G, Anton-Palma B, et al. The coelomic fluid of the sea urchin Tripneustes depressus shows antiviral activity against Suid herpesvirus type 1 (SHV-1) and rabies virus (RV). Fish Shellfish Immunol. 2014;36:158-63.

9. Watts DM, Harrison BA, Nisalak A, et al. Evaluation of Toxorhynchites splendens (Diptera: Culicidae) as a bioassay host for dengue viruses. J Med Entomol. 1982;19:54-9.

10. alazar MI, Richardson JH, Sánchez-Vargas I, et al. Dengue virus type 2: replication and tropisms in orally infected Aedes aegypti mosquitoes. BMC Microbiol. 2007;7:9.

11. Hoffmann AA, Montgomery BL, Popovici J, et al. Successful establishment of Wolbachia in Aedes populations to suppress dengue transmission. Nature. 2011;476:454-9.

12. Bryant $\mathrm{J}$, Wang $\mathrm{H}$, Cabezas $\mathrm{C}$, et al. Enzootic transmission of yellow fever virus in Peru. Emerg Infect Dis. 2003;9:926-33.

13. Auguste AJ, Lemey P, Pybus OG, et al. Yellow fever virus maintenance in Trinidad and its dispersal throughout the Americas. J Virol. 2010;84:9967-77.

14. Cardoso JDC, De Almeida MA, Santos ED, et al. Yellow fever virus in Haemagogus leucocelaenus and Aedes serratus mosquitoes, southern Brazil, 2008. Emerg Infect Dis. 2010;16:1918-24. 